\title{
Data bank: nine numerical methods for determining the parameters of weibull for wind energy generation tested by five statistical tools
}

\author{
Ahmed Samir Badawi ${ }^{1}$, Siti Hajar Yusoff ${ }^{2}$, Alhareth Mohammed Zyoud ${ }^{3}$, Sheroz Khan ${ }^{4}$, \\ Aisha Hashim $^{5}$, Yılmaz Uyaroğlu' ${ }^{6}$, Mahmoud Ismail ${ }^{7}$ \\ ${ }^{1,2,5}$ Department of Electrical and Computer Engineering, International Islamic University Malaysia, Malaysia \\ ${ }^{3}$ Department of Electrical and Computer Engineering, Birzeit University, Birzeit, Ramallah, Palestine \\ ${ }^{4}$ Department of Electrical and Renewable energy Engineering, Onaizha Collages of Engineering Al-Qassim, \\ Saudi Arabia \\ ${ }^{6}$ Electrical and Electronics Engineering Department, Sakarya University, Sakarya, Turkey \\ ${ }^{7}$ Department of Electrical Engineering Palestine Technical University, Kadoorie Tulkarm, Palestine
}

\section{Article Info}

Article history:

Received Sep 24, 2020

Revised Mar 1, 2021

Accepted Mar 15, 2021

\section{Keywords:}

Average wind speed Cumulative distribution function

Probability distribution function Numerical analysis

Statistical tools

Weibull parameters

Wind energy

\begin{abstract}
This study aims to determine the potential of wind energy in the mediterranean coastal plain of Palestine. The parameters of the Weibull distribution were calculated on basis of wind speed data. Accordingly, two approaches were employed: analysis of a set of actual time series data and theoretical Weibull probability function. In this analysis, the parameters Weibull shape factor ' $k$ ' and the Weibull scale factor ' $c$ ' were adopted. These suitability values were calculated using the following popular methods: method of moments (MM), standard deviation method (STDM), empirical method (EM), maximum likelihood method (MLM), modified maximum likelihood method (MMLM), second modified maximum likelihood method (SMMLM), graphical method (GM), least mean square method (LSM) and energy pattern factor method (EPF). The performance of these numerical methods was tested by root mean square error (RMSE), index of agreement (IA), Chi-square test $\left(\mathrm{X}^{2}\right)$, mean absolute percentage error (MAPE) and relative root mean square error (RRMSE) to estimate the percentage of error. Among the prediction techniques. The EPF exhibited the greatest accuracy performance followed by MM and MLM, whereas the SMMLM exhibited the worst performance. The RMSE achieved the best prediction accuracy, whereas the RRMSE attained the worst prediction accuracy.
\end{abstract}

This is an open access article under the CC BY-SA license.

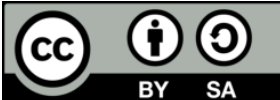

\section{Corresponding Author:}

Ahmed Samir Badawi

Department of Electrical and Computer Engineering

International Islamic University Malaysia

Jalan Gombak, 53100 Kuala Lumpur, Malaysia

Email: dr.ahmedbadawi100@gmail.com

\section{INTRODUCTION}

The electric energy crisis has emerged as a significant global problem in the last decade. Therefore, many governments tried to achieve the goal to supply an essential portion of the electrical grid from sustainable energy resources such as wind energy and PV solar system. The critical situation in the Mediterranean coastal plain of Palestine, the siege imposed and the growing need due to the high number of population for alternative sources of energy have become urgent concerns [1]. This study estimates wind 
energy production in Palestine by analyzing wind data using the expert probability function. Recently, the Weibull distribution becomes the preferred distribution in software designed for commercial wind energy, like wind atlas [2]. There is a proportional relationship between wind power extraction and the cube of wind speed, thus, the distribution of wind speed for a specific wind farm should be determined. The abscissa scale of the Weibull probability distribution is controlled by the scale parameter. The shape parameter characterises the width of the Weibull distribution, such as a large shape factor equates to a less narrow Weibull distribution with a high peak value. The following numerical methods can be used to determine the shape and scale factor for a given data series, method of moments (MM), standard deviation method (STDM), empirical method (EM), maximum likelihood method (MLM), modified maximum likelihood method (MMLM), second modified maximum likelihood method (SMMLM), graphical method (GM), least mean square method (LSM) and energy pattern factor method (EPF) [3]-[11].

The Weibull distribution is widely utilized to assess wind energy potential and analyse wind for a specific region [6], [12]-[28]. Jowder [29], applied the EM and GM to analyse the wind power density (WPD) at the altitudes of 10, 30 and 60m in the Kingdom of Bahrain. He calculated and compared two Weibull parameters then noted that the EM more accurately estimates power density and MWS than the GM. Sulaiman, et. al., [30] analysed wind speed record in Oman and referred to the concept of wind speed data following the Weibull probability distribution. Nevertheless, actual observed wind speed is not required in the Weibull distribution. Costa Rocha, et. al., [31] compared and analysed seven numerical methods to assess their performance in estimating the parameters of the Weibull probability distribution by using the actual wind speed data of Paracuru and Camocim in Brazil. Studies [32]-[34] concluded that the LSM gave better efficiency performance than MLM. Odo et. al., [35] employed a Weibull probability distribution to estimate wind energy potential for 13 years in Nigeria. Oyedepo et. al., [36] analysed the actual long-term wind data in southeast Nigeria at a height of $10 \mathrm{~m}$ from 24 to 37 years. Abbas, et. al., [37] statistically analysed the actual wind speed record in Pakistan to estimate the best fitting probability distribution of the wind speed record. They used two-parameter Weibull, Rayleigh and other types of probability distributions to fit the data. They also used MLM to determine the parameters of every distribution [34], [38]-[45]. Mostafa eipour and Mohammadi [46] utilised two methods (PDM and STDM) to assess wind record in Iran. Genc, et. al., [47], Senoglu and Kantar [48] compared several numerical methods in terms of accuracy in estimating Weibull parameters. However, the scale parameters that they applied were all less than $1.5 \mathrm{~m} / \mathrm{s}$, which is likely less than the cut-in wind speed for most small-scale wind turbines. They convened that MWS approximately $10 \%$ lower than the scale factor, if the shape factor is approximately 2 . Stathopoulos, et. al., [49] applied statistical and numerical models to estimate wind power. Zhou, et. al., [50] conducted a case study and comprehensively estimated the wind speed distribution curves for North Dakota.

Wind energy applications require the evaluation of Weibull parameters. Thus, determining the method with superior performance on shape and scale factor values is important. The Kolmogorov-Smirnov statistic test is selected to test the goodness of fit of Weibull distribution in measured data at the $1 \%$ and $5 \%$ significance levels [11]. Dorvlo [51] analysed the actual wind speed record from four different stations in Oman. He determined that the chi-square estimation method yields better estimates of Weibull parameters than the MM and GM on the basis of the Kolmogorov-Smirnov statistic. In examining the feasibility of wind energy at a specific location, the best strategy seen by calculating the WPD according to the measured information of a target meteorological location. Another strategy is the WPD using different frequency distribution functions, such as Weibull distribution, chi-square distribution, Rayleigh distribution, lognormal distribution, generalized normal distribution, gamma distribution, three-parameter lognormal distribution, kappa distribution, inverse Gaussian distribution, wake distribution, normal two-variable distribution, hybrid distribution and the normal square root of wind speed distribution [52]-[54]. Researchers have indicated that the Weibull function is better suited for the wind probability distribution in comparison with other functions [55]. The Weibull function is used to fit time series data. This distribution is essential in maintainability and reliability analyses. The appropriate values for the shape and scale parameters of the Weibull probability distribution are crucial in identifying ideal sites for the installation of wind turbine generators. The Weibull scale parameter, in particular, is essential in determining the effectiveness of wind farms [56], [57].

The available electricity generated by a wind power generation framework in a given wind field depends on the MWS, standard deviation of wind speed and installation location. Although several studies have been conducted in various Palestine territories, the authors believe that this study is the first relevant research on the Gaza Strip [58].

Wind speed data recorded from the coastal city of Ashqelon from January 2012 to December 2015. The wind industry should be describing the variations in wind speed in any location is vital for any further wind energy analysis. Such information benefits the proper selection of the wind turbine that is appropriate for this location. In this study, it can be estimated the wind energy potential in the southern coastal plain of

Data bank: nine numerical methods for determining the parameters of Weibull ... (Ahmed Samir Badawi) 
Palestine and describe how varying wind speeds can aid the optimization of wind energy turbine design for cost-effective wind energy generation.

\section{ESTIMATION OF WIND POWER DENSITY (WPD)}

WPD is a very important indicator to estimate the potential of wind speed data. Two main approaches determine the capacity of wind energy in a specific location, i) available power based on the observed MWS of the meteorological station and ii) frequency distribution function (two-parameter Weibull method) [52], [59]-[63]. In this study, we only adopted the Weibull distribution to assess wind power. Accordingly, the Weibull probability distribution function (PDF) is selected in calculating WPD and is used to illustrate the wind speed frequency distribution. To estimate Weibull parameters, nine numerical methods adopted MM, EM, MLM, MMLM, SMMLM, GM, LSM, STDM and EPF. The estimation is performed to i) distinguish past conditions retrospectively, ii) predict future power generation at one site, iii) predict power generation among a grid of wind turbines and iv) calibrate meteorological records [52], [64]-[66].

\section{WEIBULL PARAMETERS CALCULATION}

The Weibull probability distribution is a random variable that is used to describe the wind potential for a specific region. Two main parameters controlled the Weibull curve shape factor $k$ and scale factor $c$. This parameter is generally applied in statistical analyses [13], [67], [68], and its use requires time-series records of wind speed data. Based on the wind speed data collected, the Weibull probability distribution can be represented as a cumulative distribution function (CDF) or Weibull function, F(v), and Weibull PDF, $f(v)$ [27]. The CDF is obtained by computing the integral of the PDF [69]-[71], which is ultimately determined using

(1) [7,] [27], [56], [67], [69]-[72].

$$
F(v)=1-\exp \left(-\left(\frac{v}{c}\right)^{k}\right)
$$

The probability function can be derived as (2).

$$
f(v)=\frac{d F(v)}{d(v)}=k \frac{v^{(K-1)}}{c^{K}} e^{-\left(\frac{v}{c}\right)^{K}} \quad k>0, v>0, c>1
$$

Where $v, c$ and $k$ are the mean wind speed $(\mathrm{m} / \mathrm{s}), c(\mathrm{~m} / \mathrm{s}), k$ (dimensionless), respectively. Parameter $k$ indicates the width of the wind speed probability distribution, which represents the wind probability distribution peak of any specific region [71], [73], [74]. Parameter $c$ indicates the abscissa scale of the wind probability distribution, which shows the wind in particular location [71], [75]. Parameters $c$ and $k$ can be obtained using MM, STDM, EM, MLM, MMLM, SMMLM, GM, LSM and EPF. These methods are frequently compared in the literature on wind energy basis. However, the results, conclusions and recommendations of previous studies differ greatly due to the change of wind speed data conditions. Hence, it can be concluded that the appropriateness of the methods may change with the sample data distribution, sample data size, goodness-of-fit tests and sample data format [9], [52]. Based on the Weibull PDF, WPD is determined using (3) to simulate the required electric power output for wind turbine model [71], [76]-[80].

$$
\bar{P}=\frac{1}{2} \rho \int_{0}^{\infty} v^{3} f_{w}(v) d v=\frac{1}{2} \rho c^{3} \Gamma\left(1+\frac{3}{k}\right) \quad\left(\frac{\mathrm{W}}{\mathrm{m}^{2}}\right)
$$

\section{NUMERICAL METHODS FOR DETERMINING WEIBULL PARAMETERS}

\subsection{Method of moments (MM)}

The MM is recommended by Justus and Mikhail [81], [82]. The standard and mean deviations of the elements are noted initially at a suitable scale MM. On the basis of the numerical iteration of (4) and (5), the standard deviation $\sigma$ and mean $(\bar{v})$ of wind speeds are calculated [11], [67], [81], [83]-[88]. The MM is an effective approach to deriving Weibull parameters. The first moment relates to the origin, and the second 
moment pertains to the mean. These moments are used to calculate parameters $k$ and $c$, as expressed in (4) and (5) respectively. The calculation includes the MWS and standard deviation which are obtained from the calculated wind speed [88], [89].

$$
\begin{aligned}
& \bar{v}=c \Gamma(1+1 / k) \\
& \sigma=c \sqrt{\Gamma(1+2 / k)-\Gamma^{2}(1+1 / k)}
\end{aligned}
$$

where,

$$
\begin{aligned}
& \bar{v}=\frac{1}{n} \sum_{i=1}^{n} v_{i} \\
& \sigma=\sqrt{\frac{1}{n-1} \sum_{i=1}^{n}\left(v_{i}-\bar{v}\right)^{2}} \\
& \Gamma(x)=\int_{0}^{\infty} t^{x-1} \exp (-t) d t
\end{aligned}
$$

Where $\Gamma(\mathrm{x})$ is the gamma function expressed as and $v i$ is the wind speed in time step $i(\mathrm{~m} / \mathrm{s})$ and $n$ is the number of non-zero wind speed data points. The Coefficient of Variance (COV) or variation coefficient is defined as the ratio between the mean standard deviation $(\sigma)$ to average wind speed $(v)$ illustrated as a percentage. It presents the mutability of wind speed and can be illustrated as [90].

$$
\operatorname{COV}(\%)=\frac{\sigma}{v} \times 100
$$

\subsection{Empirical method (EM)}

The EM is also commonly known as the power density method. EM is easy and simple to implement [88]. The empirical approach involves a straight forward and practical solution that only requires knowledge of MWS $\bar{v}$ and standard deviation $\sigma$ [81]. The EM uses the average of the cube of wind speed $\left(v^{3}\right)$ and the cube of MWS $\bar{v}^{3}$ as Energy Pattern Factor $\left(\mathrm{E}_{\mathrm{pf}}\right)$. The scale factor is determined from the $\mathrm{E}_{\mathrm{pf}}$. The equations used to determine the scale parameter are identical to those used in the MM and EM [91]. Thus, the EM can be categorised as a special case of the MM [11], [67]. On the basis of the EM introduced by Justus [71], [92], [93], parameters $k$ and $c$ are computed using (10) and (11), respectively [71], [83], [92], [93]. In the EM, the parameters of Weibull can be estimated (10).

$$
\begin{aligned}
& k=\left(\frac{\sigma}{\bar{v}}\right)^{-1.086}, \quad 1 \leq k \leq 10 \\
& c=\frac{\bar{v}}{\Gamma\left(1-\frac{1}{k}\right)}
\end{aligned}
$$

\subsection{Maximum likelihood method (MLM)}

The MLM was put forward by Fisher [81], [94] and then introduced by Stevens and Smulders as an approach to obtain wind speed information [81], [95]. The MLM is based on the indirect results of numerical iteration methods for determining parameter $k$. Therefore, the MLM is effective despite being a laborious and complicated procedure [81]. The MLM is a mathematical formulation technique also recognized as the likelihood function in time series format for the wind speed data [71]. MLM requires extensive numerical iterations [11]. These numerical iterations are needed to estimate the parameters $k$ and $c$ of the Weibull function. Through the MLM, parameters $k$ and $c$ are calculated using (12) and (13), respectively [71], [96], [97].

$$
k=\left[\frac{\sum_{i=1}^{n} v_{i}^{k} \ln \left(v_{i}\right)}{\sum_{i=1}^{n} v_{i}^{k}}-\frac{\sum_{i=1}^{n} \ln \left(v_{i}\right)}{n}\right]^{-1}
$$

Data bank: nine numerical methods for determining the parameters of Weibull ... (Ahmed Samir Badawi) 


$$
c=\left[\frac{\sum_{i=1}^{n} v_{i}^{k}}{n}\right]^{1 / k}
$$

\subsection{Modified maximum likelihood method (MMLM)}

The MMLM is only applicable when the wind speed data are in frequency distribution format. Similar to the MLM, the MMLM entails several iterations when used to determine Weibull parameters. Parameters $k$ and $c$ are obtained using (14) and (15) [31], [71], [98].

$$
\begin{aligned}
& k=\left[\frac{\sum_{i=1}^{n} v_{i}^{k} \ln \left(v_{i}\right) f\left(v_{i}\right)}{\sum_{i=1}^{n} v_{i}^{k} f\left(v_{i}\right)}-\frac{\sum_{i=1}^{n} \ln \left(v_{i}\right) f\left(U v_{i}\right)}{f(v \geq 0)}\right]^{-1} \\
& c=\left[\frac{1}{f(v \geq 0)}-\sum_{i=1}^{n} v_{i}^{k} f\left(v_{i}\right)\right]^{1 / k}
\end{aligned}
$$

Where $v i$ is MWS central to bin $i$ and $n$ is the total number of bins, $f(v i)$ is the frequency of wind speed falling within bin $i$, where $f(v \geq 0)$ is the probability distribution curve that wind speed reaches or exceeds zero.

\subsection{Second modified maximum likelihood method (SMMLM)}

The SMMLM was developed by Christofferson and Gillette (1987) by replacing the iterative estimation of the shape parameter [99]. Which requires neither the iteration nor the sorting of data. Thus, SMMLM was selected by Hanitsch and Ahmed Shata in [100].

$$
k=\frac{\pi}{\sqrt{6}} \sqrt{\frac{N(N-1)}{N\left(\sum_{i=1}^{N} \ln ^{2} v_{i}\right)-\left(\sum_{i=1}^{N} \ln v_{i}\right)^{2}}}
$$

\subsection{Graphical method (GM)}

GM also called the LSM[101], is employed using the CDF. In GM, the wind speed record ought first to be categorised into bins. After using the logarithm of (17) twice, the GM can be obtained as. The GM is used by a logarithmic function of the CDF F(v), that is, the CDFF(v) is modulated for the inclusion of a dual logarithmic transformation [81]. Plotting $\ln (v)$ as the $x$-axis versus $\ln \{-\ln (1-F(v))\}$ as the y-axis shows a straight line in which $k$ is the slope and the y-intercept is $k \times \ln (c)$ [11], [71], [102].

$$
\ln \{-\ln [1-F(v)]\}=k \times \ln (v)-k \times \ln (c)
$$

\subsection{Energy pattern factor method (EPF)}

The EPF is related to the mean records of wind speed; it is described by (18) [9], [67].

$$
\begin{aligned}
& E_{p f}=\frac{\overline{V^{3}}}{\overline{V^{3}}} \\
& k=1+\frac{3.69}{\left(E_{p f}\right)^{2}}
\end{aligned}
$$

Where, $\bar{v}$ is given as (4), and $E_{p f}$ is the energy pattern factor and is represented by (18).

\subsection{Standard deviation method (STDM)}

In this method, $\mathrm{c}$ and $\mathrm{k}$ are calculated as in (10) and (11). Several studies have adopted STDM to calculate Weibull parameters. In [46], this method was utilised to assess wind data in Zarrineh, Iran in 2012 as mentioned. Reference [67] analysed and compared seven numerical methods to assess their effectiveness in determining the parameters of the Weibull distribution using wind data collected from Camocim and Paracuru in the northeast region of Brazil. In [11], the authors conducted a statistical study to check the 
efficiency performance by determining the Weibull shape and scale factor for six different numerical methods for wind energy applications.

\subsection{Least mean square method (LSM)}

This method determines the shape factor and scale factor based on the slope of GM. Therefore, this numerical method considers the same as GM and depends on (17) [28].

\section{GOODNESS OF FIT (GOF)}

The performance of the five parameter estimation techniques of the Weibull probability distribution for calculating WPD is evaluated using several statistical techniques, including five statistical tools indicators. To achieve a comparative assessment, we utilise the Root Mean Square Error (RMSE), Chi-square test $\left(\mathrm{X}^{2}\right)$, Index of Agreement (IA), Mean Absolute Percentage Error (MAPE), and Relative Root Mean Square Error (RRMSE), along with some other statistical tools. In the aforementioned subsections, we present a summary of the statistical tools' parameters used in this work.

\subsection{Root mean square error (RMSE)}

RMSE shows the accuracy of a model by comparing the deviations between the values gathered by the Weibull function besides those obtained from measurement data. The positive value of RMSE is calculated as in (20) [71].

$$
R M S E=\sqrt{\frac{1}{n} \sum_{i=1}^{n}\left(P_{i, W}-P_{i, M}\right)^{2}}
$$

Where $\mathrm{P}_{\mathrm{i}, \mathrm{w}}$ and $\mathrm{P}_{\mathrm{i}, \mathrm{M}}$ are the $\mathrm{i}^{\text {th }}$ calculated wind power density via WDF and the $\mathrm{i}^{\text {th }}$ calculated WPD by measured data, respectively.

\subsection{Chi-square test $\left(X^{2}\right)$}

$\mathrm{X}^{2}$ is applied to analyse proportions of independent variables, that is, possible inconsistency between the expected frequencies and observed of the events of occurrence. $X^{2}$ is a non-parametric test that is independent of factors like the average population and variance. Two series behave comparably if the variance between the frequencies for every category is negligible, therefore, close to 0 . Souza [103] indicated that for this model, the groups should be independent, the items should be randomly selected from each group, the observations should be frequently counted, and every observation should belong to only one group [81]. $\mathrm{F}(\mathrm{v})$ is the empirical probability distribution estimated from any wind speed record. Then, parameters $k$ and $c$ are determined to be minimum [104].

$$
X^{2}=\sum_{i=1}^{N} \frac{\left(y_{i, m}-x_{i, m}\right.}{x_{i, m}}
$$

Where $y$ is the observed value and $x$ is the expected value.

\subsection{Index of agreement (IA)}

The IA presents the precision degree of predicted values relative to observed values. The IA that changes from 0 to 1 is computed by [28], [71], [105].

$$
I A=1-\frac{\sum_{i=1}^{n}\left|P_{i, W}-P_{i, M}\right|}{\sqrt{\sum_{i=1}^{n}\left|P_{i, W}-P_{W, \text { avg }}\right|+\left|P_{i, M}-P_{M, \text { avg }}\right|}}
$$

Where $\mathrm{P}_{w, \text { avg }}$ and $\mathrm{P}_{M, \text { avg }}$ are the average $\mathrm{P}_{i, W}$ and $\mathrm{P}_{i, M}$ values, and $n$ is the total number of observations.

\subsection{Mean absolute percentage error (MAPE)}

MAPE presents the average absolute percentage variance between the estimated wind power using the Weibull probability function and that calculated from the observed data (measured data wind speed). MAPE can be calculated by [71]. 


$$
\text { MAPE }=\frac{1}{n} \sum_{i=1}^{n}\left|\frac{P_{i, W}-P_{i, M}}{P_{i, M}}\right| \times 100
$$

\subsection{Relative root mean square error (RRMSE)}

RRMSE can be acquired by dividing the RMSE with the mean wind power calculated by the observed values. Various domains of RRMSE can be set to demonstrate model precision according to the percentage as is clarified below [71], [106], [107]. RRMSE is considered, excellent if the efficiency performance is less than 10\%, Good if $10 \%<$ RRMSE < 20\%, average if $20 \%<$ RRMSE < $30 \%$ and Poor if RRMSE is more than $30 \%$. RRMSE, MAPE, IA, $X^{2}$, and RMSE with values close to zero are considered satisfactory [27].

$$
\text { RRMSE }=\frac{\sqrt{\frac{1}{n} \sum_{i=1}^{n}\left(P_{i, W}-P_{i, M}\right)^{2}}}{\frac{1}{n} \sum_{i=1}^{n} P_{i, M}} \times 100
$$

\section{RESULTS AND DISCUSSION}

\subsection{Mean wind speed (MWS) for Asqelon city}

Wind speed records from wind monitoring stations are adopted to identify the most ideal numerical method for the Weibull distribution. Wind speed data in Ashqelon was recorded from January 2012 to December 2015. Wind speed data from Ashqelon during the period of January 2012 to December 2015 are selected and used in performance testing. Nine numerical methods used in the statistical analysis are employed to compute the $c$ and $k$ parameters of the Weibull curve.

The nine techniques had been tested to check the percentage of error based on five statistical tools. The statistical tools are RMSE, $\mathrm{X}^{2}$, IA, MAPE and RRMSE. The ranking is performed using the aforementioned statistical tools to ensure an accurate diagnosis. Figure 1 shows the percentage of the monthly MWS of Ashqelon in the coastal plain of Palestine between 2012 and 2015. The sources of the meteorological data on Ashqelon, which is adjacent to Gaza City, are recorded on a daily basis according to the MWS that is usually calculated every month. The graph shows that MWS dramatically decreased from February-April 2012, reaching an all-time low of 3.2m/s. In January, MWS rose as high as or more than $5 \mathrm{~m} / \mathrm{s}$. MWS increased steadily and reached approximately $4 \mathrm{~m} / \mathrm{s}$. In the last three months, the curve declined. In April 2013, MWS increased dramatically, reaching around $4.7 \mathrm{~m} / \mathrm{s}$. The curve suddenly fluctuated during the last eight months of the year. In January to August 2014, MWS significantly increased, reaching $4.8 \mathrm{~m} / \mathrm{s}$ before finally dropping in the last four months of the year. In January 2015, MWS jumped and reached $5.1 \mathrm{~m} / \mathrm{s}$. It then fluctuated significantly and reached a peak point in June. However, MWS gradually declined between July and December, reaching an all-time low of $3 \mathrm{~m} / \mathrm{s}$. Overall, MWS fluctuated between $3-5 \mathrm{~m} / \mathrm{s}$ during this period. Wind speed in this area is generally below $15 \mathrm{~m} / \mathrm{s}$, and strong wind speed does not exceed $25 \mathrm{~m} / \mathrm{s}$. Figure 2 illustrates the frequency distribution of the actual MWS records of Ashqelon between January 2012 and December 2015. The bar graph is extremely close to the Weibull curve (PDF) of the wind speed data. More than $90 \%$ of the frequency lies between 1 and $7 \mathrm{~m} / \mathrm{s}$ of wind speed for four years.

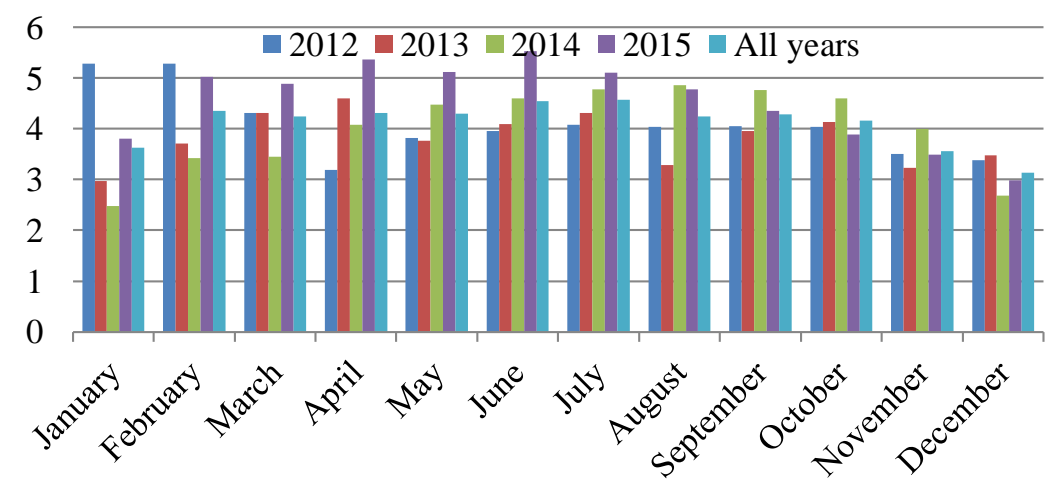

Figure 1. MWS in Ashqelon from January 2012 to December 2015 [108] 


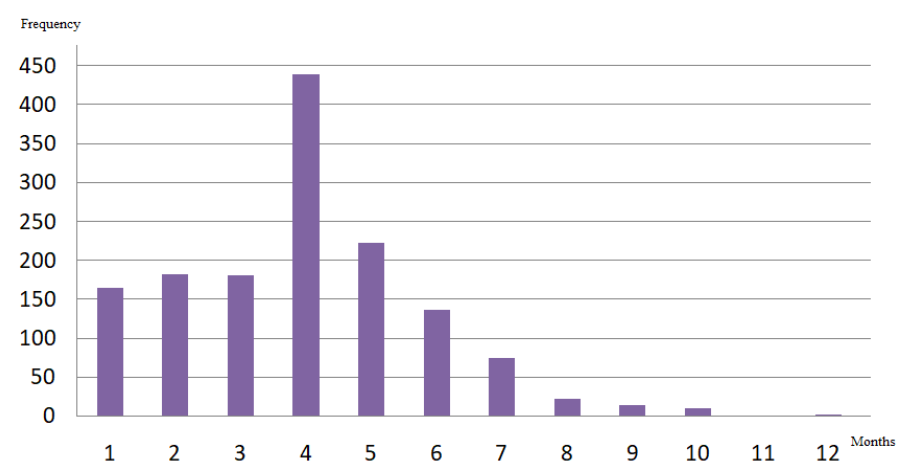

Figure 2. Frequency of actual MWS records from January 2012 to December 2015

\subsection{PDF and CDF for Ashqelon city}

Measured and estimated cumulative distribution function (CDF) and probability distribution function (PDF) have been investigated using nine numerical methods for the Ashkelon site from 2012-2015. Figure 3 shows PDF for Ashqelon city for the four years. The PDF is represented the Weibull curve using nine numerical methods based on shape factor value (around 2). The red line is represented as the observed PDF, $x$-axis is wind speed and $y$-axis is PDF values. It can be seen that the peak of the curve at $4 \mathrm{~m} / \mathrm{s}$. This study has been conducted a statistical Weibull analysis of the wind speed data plots of the PDF and CDF for the entire data and seasons. Figure 4 represents the CDF for the four years. The red curve is the observed CDF. This curve is considered the integral of Weibull PDF as (1).

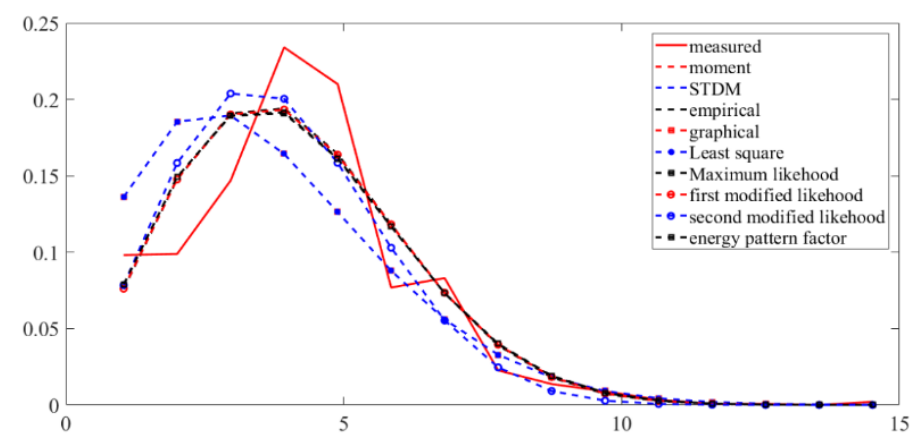

Figure 3. Comparison between observed and estimated PDF curves for Ashqelon from 2012 to 2015

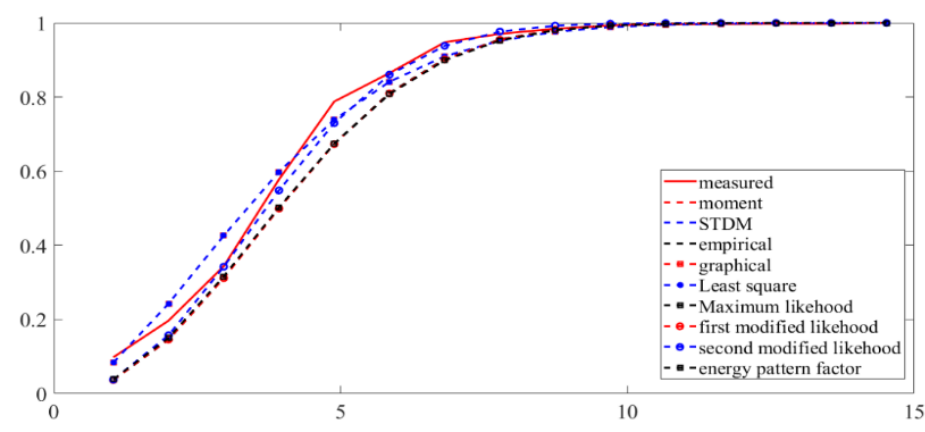

Figure 4. Comparison between observed and estimated CDF curves for Ashqelon from 2012 to 2015

Table 1 presents the variations in the values of the Weibull shape factor $k$ and scale $c$ parameters, along with the standard deviations of the measured data and Weibull results for both site analyses in 2012.

Data bank: nine numerical methods for determining the parameters of Weibull ... (Ahmed Samir Badawi) 
The shape parameter lies between 2.0608 and 2.2526, this means that the Figures are Weibull as mentioned in Figure 3 and the scale parameter is between $4.1000 \mathrm{~m} / \mathrm{s}$ and $4.7555 \mathrm{~m} / \mathrm{s}$. There are three cases for the shape factors control the PDF curve, a) $k \leq 1$ PDF is exponential, b) $1<\mathrm{k} \leq 2$ PDF is Weibull (the most common curve) and c) k>2 PDF is bell-shape distribution or Gaussian. Different wind parameters reflect dissimilar wind turbine systems or energy potential. Estimating these parameters accurately for a particular period is necessary for wind energy applications. Table 2 shows that the scale and shape factors $(4.3119 \mathrm{~m} / \mathrm{s}$ and 2.1006, respectively) of the MLM are completely identical to the observed values in 2013. The standard deviation for 2013 ranges from $1.7264 \mathrm{~m} / \mathrm{s}$ to $1.9224 \mathrm{~m} / \mathrm{s}$, whereas the observed value is $1.9179 \mathrm{~m} / \mathrm{s}$. Table 3 indicate that $k$ and $c$ are nearly the same for the MM, STDM, EM, MLM and EPF. The results of the MM, STDM, EM, MLM and EPF are close and are better than those of the other methods. Table 4 shows the value of the Weibull parameter for 2015. Standard deviation and variation coefficient have been calculated using each numerical technique. The shape factor is around 2 and the scale factor is from $4.4-5.1 \mathrm{~m} / \mathrm{s}$. It can be seen that EM and STDM have the same result from Table 1 to Table 4. Moreover, GM and LSM have the same result as mentioned in Section 4.9. Table 1 to Table 4 indicate that $k$ and $c$ are nearly the same for the MM, STDM, EM, MLM and EPF. The results of the MM, STDM, EM, MLM and EPF are close and better than those of the other methods.

The parameters of Weibull can be calculated using the GM of every year as shown in Figure 5 to Figure 8. The method to calculate the shape and scale factor is to plot the natural logarithm of the observed speed versus $\ln (-\ln (1-\mathrm{F}(v))$. Therefore, the Weibull parameters can be found by linearly fitting the plotted points; thus, $k$ is the slope of the fitted line, and $c$ is equal to $\exp (\mathrm{b} / \mathrm{k})$, where $\mathrm{b}$ is the $\mathrm{y}$-intercept of the fitted line. Where, $\ln (v)$ as $x$ axis versus $\ln (-\ln (1-\mathrm{F}(v))$.

Table 1. Estimation of Weibull parameters, standard deviation $\sigma$ and Coefficient of variance (COV) for 2012

\begin{tabular}{lccccc}
\hline \multirow{2}{*}{2012} & \multicolumn{5}{c}{ Estimated $c$ and $k$ using the nine numerical methods } \\
& $c(\mathrm{~m} / \mathrm{s})$ & $k$ & MWS $(\mathrm{m} / \mathrm{s})$ & $\sigma(\mathrm{m} / \mathrm{s})$ & COV $(\%)$ \\
\hline MM & 4.5988 & 2.0608 & 4.0738 & 2.0729 & 50.8836 \\
EM & 4.5991 & 2.0725 & 4.0738 & 2.0624 & 50.6248 \\
MLM & 4.6053 & 2.0616 & 4.0795 & 2.0751 & 50.8663 \\
MMLM & 4.7555 & 2.3526 & 4.2142 & 1.9041 & 45.1831 \\
SMMLM & 4.1000 & 2.2322 & 3.6313 & 1.7198 & 47.3613 \\
GM & 4.3642 & 1.7848 & 3.8827 & 2.2492 & 57.9291 \\
EPF & 4.5946 & 1.9559 & 4.0738 & 2.1727 & 53.3336 \\
STDM & 4.5991 & 2.0725 & 4.0738 & 2.0624 & 50.6248 \\
LSM & 4.3642 & 1.7848 & 3.8827 & 2.2492 & 57.9291 \\
Observed & 4.6053 & 2.0616 & 4.0800 & 1.9873 & 51.1173 \\
\hline
\end{tabular}

Table 2. Estimation of Weibull parameters, $\sigma$ and COV for 2013

\begin{tabular}{lccccc}
\hline \multirow{2}{*}{2013} & \multicolumn{5}{c}{ Estimated $c$ and $k$ using the nine numerical methods } \\
& $c(\mathrm{~m} / \mathrm{s})$ & $k$ & MWS $(\mathrm{m} / \mathrm{s})$ & $\sigma(\mathrm{m} / \mathrm{s})$ & COV $(\%)$ \\
\hline MM & 4.3076 & 2.0990 & 3.8152 & 1.9095 & 50.0496 \\
EM & 4.3077 & 2.1105 & 3.8152 & 1.9002 & 49.8045 \\
MLM & 4.3119 & 2.1006 & 3.8190 & 1.9101 & 50.0166 \\
MMLM & 4.3513 & 2.1937 & 3.8536 & 1.8538 & 48.1071 \\
SMMLM & 4.0403 & 2.1865 & 3.5781 & 1.7264 & 48.2480 \\
GM & 3.7570 & 1.8225 & 3.3391 & 1.8981 & 56.8458 \\
EPF & 4.3074 & 2.0834 & 3.8152 & 1.9224 & 50.3863 \\
STDM & 4.3077 & 2.1105 & 3.8152 & 1.9002 & 49.8045 \\
LSM & 3.7570 & 1.8225 & 3.3391 & 1.8981 & 56.8458 \\
Observed & 4.3119 & 2.1006 & 3.8200 & 1.9179 & 50.2685 \\
\hline
\end{tabular}

Table 3. Estimation of Weibull parameters, $\sigma$ and COV for 2014

\begin{tabular}{lccccc}
\hline \multirow{2}{*}{2014} & \multicolumn{5}{c}{ Estimated $c$ and $k$ using the nine numerical methods } \\
& $c$ & $k$ & MWS $(\mathrm{m} / \mathrm{s})$ & $\sigma(\mathrm{m} / \mathrm{s})$ & COV $(\%)$ \\
\hline MM & 4.5376 & 2.2464 & 4.0190 & 1.8927 & 47.0934 \\
EM & 4.5374 & 2.2570 & 4.0190 & 1.8847 & 46.8951 \\
MLM & 4.5231 & 2.2089 & 4.0058 & 1.9152 & 47.8094 \\
MMLM & 4.4696 & 2.0668 & 3.9592 & 2.0093 & 50.7497 \\
SMMLM & 4.2750 & 2.2924 & 3.7872 & 1.7514 & 46.2446 \\
GM & 3.8086 & 1.6942 & 3.3990 & 2.0644 & 60.7359 \\
EPF & 4.5375 & 2.2536 & 4.0190 & 1.8873 & 46.9588 \\
STDM & 4.5374 & 2.2570 & 4.0190 & 1.8847 & 46.8951 \\
LSM & 3.8086 & 1.6942 & 3.3990 & 2.0644 & 60.7359 \\
Observed & 4.5231 & 2.2089 & 4.0200 & 1.8993 & 47.2570 \\
\hline
\end{tabular}


Table 4. Estimation of Weibull parameters, $\sigma$ and COV for 2015

\begin{tabular}{lccccc}
\hline \multirow{2}{*}{2015} & \multicolumn{5}{c}{ Estimated $c$ and $k$ using the nine numerical methods } \\
& $\mathrm{c}$ & $\mathrm{k}$ & MWS $(\mathrm{m} / \mathrm{s})$ & $\sigma(\mathrm{m} / \mathrm{s})$ & $\mathrm{COV}(\%)$ \\
\hline MM & 5.0981 & 2.4321 & 4.5205 & 1.9827 & 43.8593 \\
EM & 5.0977 & 2.4414 & 4.5205 & 1.9759 & 43.7096 \\
MLM & 5.0839 & 2.3990 & 4.5068 & 2.0010 & 44.3994 \\
MMLM & 5.0234 & 2.2321 & 4.4491 & 2.1073 & 47.3645 \\
SMMLM & 4.8565 & 2.4650 & 4.3075 & 1.8666 & 43.3344 \\
GM & 4.4173 & 1.9389 & 3.9174 & 2.1057 & 53.7534 \\
EPF & 5.0981 & 2.4315 & 4.5205 & 1.9831 & 43.8692 \\
STDM & 5.0977 & 2.4414 & 4.5205 & 1.9759 & 43.7096 \\
LSM & 4.4173 & 1.9389 & 3.9174 & 2.1057 & 53.7534 \\
Observed & 5.0839 & 2.3990 & 4.5300 & 1.9873 & 43.9606 \\
\hline
\end{tabular}

$$
y=m x-b
$$

Where $x=$ slope, $k=$ slope $b=k \ln (c)$.

$$
\begin{aligned}
& \ln (c)=\frac{b}{k} \\
& c=e^{\frac{b}{k}}
\end{aligned}
$$

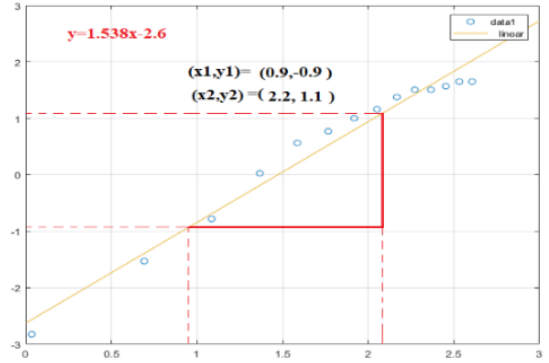

Figure 5. GM estimated results for Ashqelon in 2012

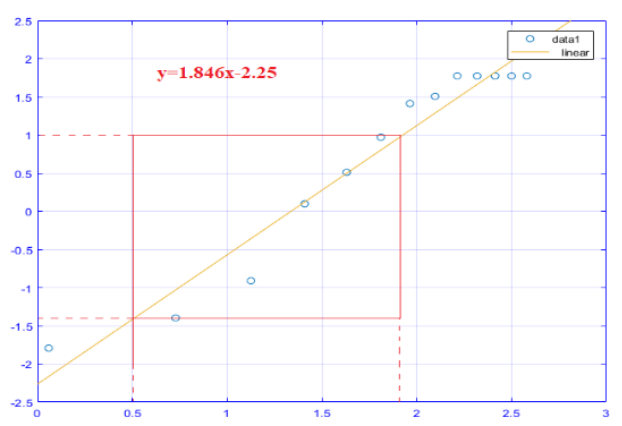

Figure 7. GM estimated results for Ashqelon in 2014

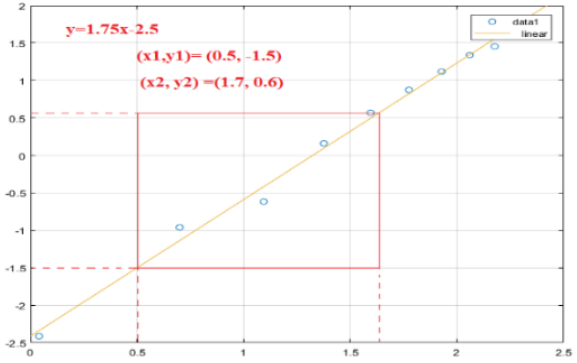

Figure 6. GM estimated results for Ashqelon in 2013

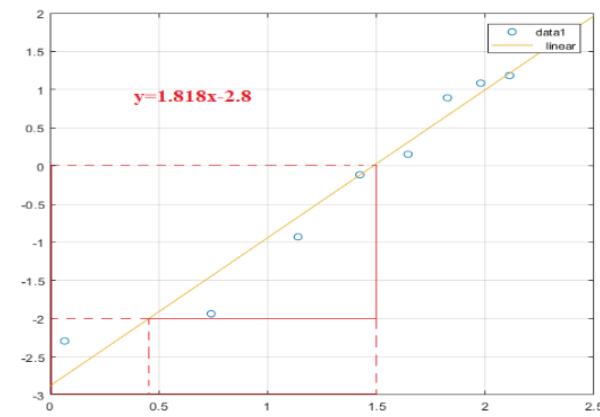

Figure 8. GM estimated results for Ashqelon in 2015

Table 5 to Table 8 show the percentage of error based on the analysis of the five statistical techniques for nine numerical methods. Table 5 shows that the GM and LSM yield the greatest efficiency according to the RMSE, X2, IA and RRMSE in 2012. It is followed by EPF, MLM, MM, EM and STDM. The method with the worst efficiency reflected in the RMSE, $\mathrm{X}^{2}$ and RRMSE is the SMMLM, followed by the MMLM. The ranking had been preceded on the basis of the percentage of error for each method. The wind speed effect in the efficiency for each method, in the other word it's difficult to approve that a specific method as the best one due to change wind speed condition.

Data bank: nine numerical methods for determining the parameters of Weibull ... (Ahmed Samir Badawi) 
Table 6 shows that GM and LSM achieve the best efficiency according to the RMSE in 2013. It is followed by EPF, MM, MLM SRDM and EM. The MM, STDM, EM and MLM showed approximately the same efficiency performance according to the RMSE, $X^{2}$, IA and MAPE in 2013. The SMMLM shows the worst efficiency performance according to the RMSE, $X^{2}$, IA and RRMSE.

In terms of the RMSE in 2014, the STDM and GM exhibit the best efficiency performance, followed by the EPF, MM and MLM as shown in Table 7. The SMMLM shows the lowest efficiency performance according to the RRMSE, $\mathrm{X}^{2}$ and RMSE. Table 8 shows that in terms of the RMSE in 2015, the STDM and GM present the highest efficiency performance by the EPF, MM and MLM. By contrast, the SMMLM shows the lowest efficiency performance.

Table 5. Error percentage for checking accurate numerical methods in 2012

\begin{tabular}{|c|c|c|c|c|c|c|c|c|c|c|c|}
\hline \multirow{2}{*}{\multicolumn{2}{|c|}{$\begin{array}{c}2012 \\
\text { Numerical } \\
\text { methods }\end{array}$}} & \multicolumn{10}{|c|}{ Goodness of fit tests for Coastal plain of Palestine- Ashqelon 2012} \\
\hline & & \multirow{2}{*}{$\begin{array}{l}\text { RMSE } \\
0.0074\end{array}$} & \multirow{2}{*}{$\frac{\text { Ranking }}{3}$} & \multirow{2}{*}{$\frac{\mathrm{X}^{2}}{0.9780}$} & \multicolumn{3}{|c|}{ Comparative analysis } & \multirow{2}{*}{$\begin{array}{l}\text { MAPE } \\
0.0196\end{array}$} & \multirow{2}{*}{$\frac{\text { Ranking }}{3}$} & \multirow{2}{*}{$\begin{array}{c}\text { RRMSE } \\
11.1391\end{array}$} & \multirow{2}{*}{$\frac{\text { Ranking }}{3}$} \\
\hline 1 & $\mathrm{MM}$ & & & & 4 & 0.7893 & 3 & & & & \\
\hline 3 & MLM & 0.0074 & 3 & 0.9610 & 3 & 0.7895 & 4 & 0.0196 & 3 & 11.1577 & 4 \\
\hline 4 & MMLM & 0.0089 & 5 & 13.5805 & 6 & 0.8316 & 6 & 0.0158 & 1 & 13.3614 & 6 \\
\hline 5 & SMMLM & 0.0223 & 6 & 222.8923 & 7 & 0.7795 & 2 & 0.0215 & 5 & 33.3957 & 7 \\
\hline 7 & $\mathrm{EPF}$ & 0.0066 & 2 & 0.4346 & 2 & 0.7705 & 2 & 0.0212 & 4 & 9.9210 & 2 \\
\hline 8 & STDM & 0.0075 & 4 & 1.0926 & 5 & 0.7912 & 5 & 0.0194 & 2 & 11.2563 & 5 \\
\hline 9 & LSM & 0.0043 & 1 & 0.3073 & 1 & 0.7415 & 1 & 0.0239 & 6 & 6.4394 & 1 \\
\hline
\end{tabular}

Table 6. Error percentage for checking accurate numerical methods in 2013

\begin{tabular}{|c|c|c|c|c|c|c|c|c|c|c|c|}
\hline \multirow{2}{*}{\multicolumn{2}{|c|}{$\begin{array}{c}2013 \\
\text { Numerical } \\
\text { methods }\end{array}$}} & \multicolumn{10}{|c|}{ Goodness of fit tests for Coastal plain of Palestine- Ashqelon 2013} \\
\hline & & \multirow{2}{*}{$\begin{array}{l}\text { RMSE } \\
0.0053\end{array}$} & \multirow{2}{*}{$\frac{\text { Ranking }}{3}$} & \multirow{2}{*}{$\frac{X^{2}}{0.1393}$} & \multicolumn{3}{|c|}{ Comparative analysis } & \multirow{2}{*}{$\begin{array}{l}\text { MAPE } \\
0.0317\end{array}$} & \multirow{2}{*}{$\frac{\text { Ranking }}{3}$} & \multirow{2}{*}{$\begin{array}{c}\text { RRMSE } \\
5.2971\end{array}$} & \multirow{2}{*}{$\frac{\text { Ranking }}{5}$} \\
\hline 1 & MM & & & & 2 & 0.7229 & 4 & & & & \\
\hline 3 & MLM & 0.0053 & 3 & 0.1393 & 2 & 0.7224 & 3 & 0.0318 & 4 & 5.3135 & 3 \\
\hline 4 & MMLM & 0.0063 & 5 & 0.1493 & 4 & 0.7254 & 6 & 0.0317 & 3 & 6.2557 & 6 \\
\hline 5 & SMMLM & 0.0071 & 6 & 0.2126 & 6 & 0.7509 & 7 & 0.0295 & 1 & 7.1193 & 7 \\
\hline 8 & STDM & 0.0054 & 4 & 0.1402 & 3 & 0.7239 & 5 & 0.0316 & 2 & 5.4297 & 4 \\
\hline 9 & LSM & $3.2001 \mathrm{e}-04$ & 1 & 0.1916 & 5 & 0.7027 & 1 & 0.0352 & 5 & 0.3200 & 1 \\
\hline
\end{tabular}

Table 7. Error percentage for checking accurate numerical methods in 2014

\begin{tabular}{|c|c|c|c|c|c|c|c|c|c|c|c|}
\hline \multirow{3}{*}{\multicolumn{2}{|c|}{$\begin{array}{c}2014 \\
\text { Numerical } \\
\text { methods }\end{array}$}} & \multicolumn{10}{|c|}{ Goodness of fit tests for Coastal plain of Palestine- Ashqelon 2014} \\
\hline & & \multirow{3}{*}{$\begin{array}{l}\text { RMSE } \\
0.0046\end{array}$} & \multirow{3}{*}{$\frac{\text { Ranking }}{2}$} & \multirow{3}{*}{$\frac{X^{2}}{1.9073}$} & \multirow{3}{*}{$\frac{\text { Ranking }}{6}$} & \multicolumn{2}{|c|}{ Comparative analysis } & \multirow{3}{*}{$\begin{array}{l}\text { MAPE } \\
0.0323\end{array}$} & \multirow{3}{*}{$\frac{\text { Ranking }}{1}$} & \multirow{3}{*}{$\begin{array}{c}\text { RRMSE } \\
6.4148\end{array}$} & \multirow{3}{*}{$\frac{\text { Ranking }}{3}$} \\
\hline & & & & & & IA & Ranking & & & & \\
\hline 1 & $\mathrm{MM}$ & & & & & 0.6761 & 5 & & & & \\
\hline 2 & EM & 0.0045 & 1 & 2.1563 & 5 & 0.6764 & 6 & 0.0323 & 1 & 6.3530 & 1 \\
\hline 3 & MLM & 0.0048 & 3 & 1.3660 & 3 & 0.6751 & 4 & 0.0324 & 2 & 6.6635 & 4 \\
\hline 4 & MMLM & 0.0056 & 4 & 0.5520 & 1 & 0.6723 & 3 & 0.0325 & 3 & 7.8650 & 5 \\
\hline 5 & SMMLM & 0.0304 & 6 & 22.2735 & 7 & 0.6501 & 2 & 0.0347 & 4 & 42.6080 & 7 \\
\hline 6 & GM & 0.0117 & 5 & 0.5048 & 2 & 0.6119 & 1 & 0.0389 & 5 & 16.3687 & 6 \\
\hline 7 & $\mathrm{EPF}$ & 0.0046 & 2 & 2.0717 & 4 & 0.6764 & 6 & 0.0323 & 1 & 6.3728 & 2 \\
\hline 8 & STDM & 0.0045 & 1 & 2.1563 & 5 & 0.6764 & 6 & 0.0323 & 1 & 6.3530 & 1 \\
\hline 9 & LSM & 0.0117 & 5 & 0.5048 & 2 & 0.6119 & 1 & 0.0389 & 5 & 16.3687 & 6 \\
\hline
\end{tabular}

Table 8. Error percentage for checking accurate numerical methods in 2015

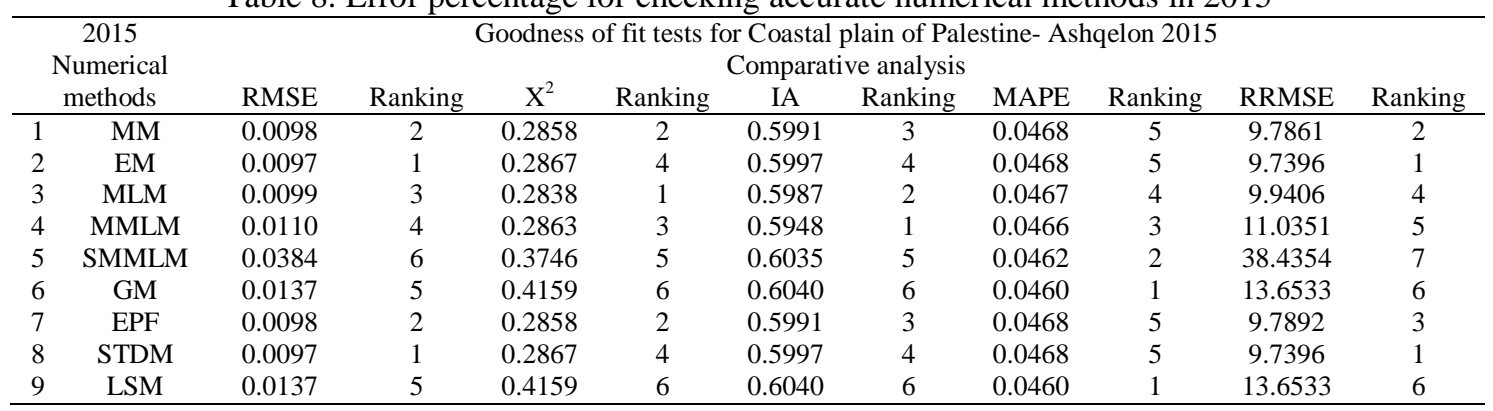




\section{CONCLUSION}

Nine numerical techniques had been used to calculate the Weibull parameter for Ashqelon site. The PDF and CDF had been implemented using nine numerical methods for Ashqelon site from 2012 to 2015. The percentage of error had been calculated using five statistical tools to check the efficiency performance for the numerical techniques. GM and energy pattern factor EPF show the greatest efficiency, whereas the SMMLM shows the lowest efficiency based on statistical tools. Between 2014 and 2015. The EM and STDM show the best efficiency performance, followed by MM and MLM. Based on numerical analysis shape factor $k$ is approximately 2. Therefore, the PDF for Palestine is Weibull, whereas, scale factor $c$ value from 4 to 5 $\mathrm{m} / \mathrm{s}$. The MWS speed at Ashqelon was $4.07 \mathrm{~m} / \mathrm{s}, 3.82 \mathrm{~m} / \mathrm{s}, 4.02 \mathrm{~m} / \mathrm{s}$ and $4.52 \mathrm{~m} / \mathrm{s}$ for the year 2012, 2013, 2014 and 2015 respectively. The EPF applies to the assessment of any wind speed data and shows the greatest accuracy performance through the years followed by MM and MLM. The SMMLM presents the worst prediction performance followed by MMLM according to all statistical techniques. Among the five statistical tools, RMSE is the most accurately predicted technique. By contrast, the worst predicted technique is RRMSE. This research determined the wind energy conversion characteristics. Based on WPD calculations this study confirms the potential of electrical energy generation in Palestine using small-scale turbines.

\section{REFERENCES}

[1] Badawi A. S., Hasbullah, N. F. Yusoff S., Hashim A., and Elamassie M, "Practical electrical energy production to solve the shortage in electricity in Palestine and payback period," International Journal of Electrical and Computer Engineering, vol. 9, no. 6, pp. 4610-4616, 2019, DOI: 10.11591/ijece.v9i6.pp4610-4616.

[2] Carta, J. A., P. Ramirez, and S. Velazquez, "A review of wind speed probability distributions used in wind energy analysis: case studies in the Canary Islands," Renewable and Sustainable Energy Reviews, vol. 13, no. 5, p. 933955, 2009, DOI: 10.1016/j.rser.2008.05.005.

[3] Zhou, W., H. Yang, and Z. Fang, "Wind power potential and characteristic analysis of the Pearl River Delta region, China," Renewable Energy, vol. 31, no. 6, pp. 739-753, 2006, DOI: 10.1016/j.renene.2005.05.006.

[4] Akpinar, E. K. and S. Akpinar, "Determination of the wind energy potential for Maden-Elazig, Turkey," Energy Conversion and Management, vol. 45, no. 18-19, pp. 2901-2914, 2004, DOI: 10.1016/j.enconman.2003.12.016.

[5] Ucar, A. and F. Balo, "Investigation of wind characteristics and assessment of wind-generation potentiality in Uludağ-Bursa, Turkey," Applied Energy, vol. 86, no. 3, pp. 333-339, 2009, DOI: 10.1016/j.apenergy.2008.05.001.

[6] Tsang-Jung Changa, Yu-Ting Wua, Hua-Yi Hsua, Chia-Ren Chub, Chun-Min Liaoa, "Assessment of wind characteristics and wind turbine characteristics in Taiwan," Renewable Energy, vol. 28, no. 6, pp. 851-871, 2003, DOI: 10.1016/S0960-1481(02)00184-2.

[7] Kwon, S. D., "Uncertainty analysis of wind energy potential assessment," Applied Energy, vol. 87, no. 3, pp. 856-865, 2010, DOI: 10.1016/j.apenergy.2009.08.038.

[8] L. Thiaw, G. Sow, S. S. Fall, M. Kasse, E. Sylla and S. Thioye, "A neural network based approach for wind resource and wind generators production assessment," Applied Energy, vol. 87, no. 5, pp. 1744-1748, 2010, DOI: 10.1016/j.apenergy.2009.10.001.

[9] Akdağ S. A., and A. Dinler, "A new method to estimate Weibull parameters for wind energy applications," Energy Conversion and Management, vol. 50, no. 7, pp. 1761-1766, 2009, DOI: 10.1016/j.enconman.2009.03.020.

[10] Seguro, J. and T. Lambert, "Modern estimation of the parameters of the Weibull wind speed distribution for wind energy analysis," Journal of Wind Engineering and Industrial Aerodynamics, vol. 85, no. 1, pp. 75-84, 2000. DOI: 10.1016/S0167-6105(99)00122-1.

[11] Chang, T.P., "Performance comparison of six numerical methods in estimating Weibull parameters for wind energy application," Applied Energy, vol. 88, no. 1, pp. 272-282, 2011, DOI: 10.1016/j.apenergy.2010.06.018.

[12] Islam M. R., R. Saidur, and N. A. Rahim, "Assessment of wind energy potentiality at Kudat and Labuan, Malaysia using Weibull distribution function," Energy, vol. 36, no. 2, pp. 985-992, 2011, DOI: 10.1016/j.energy.2010.12.011.

[13] Celik, A. N., "A statistical analysis of wind power density based on the Weibull and Rayleigh models at the southern region of Turkey," Renewable Energy, vol. 29, no. 4, pp. 593-604, 2004, DOI: 10.1016/j.renene.2003.07.002.

[14] Sardar Maran P, and R. Ponnusamy, "Wind power density estimation using meteorological tower data," Int. J. Renew. Sustain. Energy, vol. 2, no. 3, pp. 110-114, 2013, DOI: 10.11648/j.ijrse.20130203.15.

[15] S. Bivona, G. Bonanno, R. Burlon, D. Gurrera, C. Leone, "Stochastic models for wind speed forecasting," Energy conversion and management, vol. 52, no. 2, pp. 1157-1165, 2011, DOI: 10.1016/j.enconman.2010.09.010.

[16] Daniel A. and A. A. Chen, "Stochastic simulation and forecasting of hourly average wind speed sequences in Jamaica," Solar Energy, vol. 46, no. 1, pp. 1-11, 1991, DOI: 10.1016/0038-092X(91)90101-2.

[17] Kamal, L. and Y. Z. Jafri, "Time series models to simulate and forecast hourly averaged wind speed in Quetta, Pakistan,” Solar Energy, vol. 61, no. 1, pp. 23-32, 1997, DOI: 10.1016/S0038-092X(97)00037-6.

[18] Cadenas, E. and W. Rivera, "Wind speed forecasting in the south coast of Oaxaca, Mexico," Renewable Energy, vol. 32, no. 12, pp. 2116-2128, 2007, DOI: 10.1016/j.renene.2006.10.005

[19] Alexiadis, M., P. Dokopoulos and H. Sahsamanoglou, "Wind speed and power forecasting based on spatial correlation models," IEEE Transactions on Energy Conversion, vol. 14, no. 3, pp. 836-842, 1999, DOI: $10.1109 / 60.790962$. 
[20] A. Keyhani, M. Ghasemi-Varnamkhasti, M. Khanali and R. Abbaszadeh, "An assessment of wind energy potential as a power generation source in the capital of Iran, Tehran," Energy, vol. 35, no. 1, pp. 188-201, 2010, DOI: 10.1016/j.energy.2009.09.009.

[21] Mirhosseini, M., F. Sharifi and A. Sedaghat, "Assessing the wind energy potential locations in province of Semnan in Iran," Renewable and Sustainable Energy Reviews, vol. 15, no. 1, pp. 449-459, 2011, DOI: 10.1016/j.rser.2010.09.029.

[22] Alamdari P, O. Nematollahi and M. Mirhosseini, “Assessment of wind energy in Iran: A review," Renewable and Sustainable Energy Reviews, vol. 16, no. 1, pp. 836-860, 2012, DOI: 10.1016/j.rser.2011.09.007.

[23] Jaramillo O., R. Saldaña and U. Miranda, "Wind power potential of baja california sur, mexico," Renewable Energy, vol. 29, no. 13, pp. 2087-2100, 2004, DOI: 10.1016/j.renene.2004.03.004.

[24] Akpinar S., and E. K. Akpinar, "Estimation of wind energy potential using finite mixture distribution models," Energy Conversion and Management, vol. 50, no. 4, pp. 877-884, 2009, DOI: 10.1016/j.enconman.2009.01.007.

[25] Weisser D, "A wind energy analysis of Grenada: an estimation using the 'Weibull'density function," Renewable Energy, vol. 28, no. 11, pp. 1803-1812, 2003, DOI: 10.1016/S0960-1481(03)00016-8.

[26] Mathew S., and K. Pandey, “Analysis of wind regimes for energy estimation," Renewable Energy, vol. 25, no. 3, pp. 381-399, 2002, DOI: 10.1016/S0960-1481(01)00063-5.

[27] Azad, A., M. Rasul, and T. Yusaf, "Statistical diagnosis of the best weibull methods for wind power assessment for agricultural applications," Energies, vol. 7, no. 5, pp. 3056-3085, 2014, DOI: 10.3390/en7053056.

[28] Badawi A. S. A., "Maximum power point tracking control scheme for small scale wind turbine," Thesis for: PhD, International Islamic University Malaysia, 2019.

[29] Jowder F. A., "Wind power analysis and site matching of wind turbine generators in Kingdom of Bahrain," Applied Energy, vol. 86, no. 4, pp. 538-545, 2009, DOI: 10.1016/j.apenergy.2008.08.006.

[30] M. Yusof Sulaiman, Ahmed Mohammed Akaak, Mahdi Abd Wahab, Azmi Zakaria, Z. Abidin Sulaiman, Jamil Suradi, "Wind characteristics of Oman," Energy, vol. 27, no. 1, pp. 35-46, 2002, DOI: $10.1016 / \mathrm{S} 0360-5442(01) 00055-\mathrm{X}$.

[31] Paulo Alexandre Costa Rocha, Ricardo Coelho de Sousa, Carla Freitas de Andrade and Maria Eugênia Vieirada Silva, "Comparison of seven numerical methods for determining Weibull parameters for wind energy generation in the northeast region of Brazil," Applied Energy, vol. 89, no. 1, pp. 395-400, 2012, DOI: 10.1016/j.apenergy.2011.08.003.

[32] Bhattacharya P., and R. Bhattacharjee, "A study on Weibull distribution for estimating the parameters," Wind Engineering, vol. 33, no. 5, pp. 469-476, 2009, DOI: 10.1260/030952409790291163.

[33] Chu Y.-K., and J.-C., Ke, "Computation approaches for parameter estimation of Weibull distribution," Mathematical and Computational Applications, vol. 17, no. 1, pp. 39-47, 2012.

[34] Cohen A.C., "Maximum likelihood estimation in the Weibull distribution based on complete and on censored samples," Technometrics, vol. 7, no. 4, pp. 579-588, 1965.

[35] Odo F., S. Offiah and P. Ugwuoke, "Weibull distribution-based model for prediction of wind potential in Enugu, Nigeria," Advances in Applied Science Research, vol. 3, no. 2, pp. 1202-1208, 2012.

[36] Oyedepo S. O., M. S. Adaramola and S. S. Paul, "Analysis of wind speed data and wind energy potential in three selected locations in south-east Nigeria," International Journal of Energy and Environmental Engineering, vol. 3, no. 1, p. 2-11, 2012, DOI: 10.1186/2251-6832-3-7.

[37] Kamran Abbas, Alamgir, Sajjad Ahmad Khan, Amjad Ali, Dost Muhammad Khan and Umair Khalil, "Statistical analysis of wind speed data in Pakistan," World Applied Sciences Journal, vol. 18, no. 11, pp. 1533-1539, 2012, DOI: 10.5829/idosi.wasj.2012.18.11.2040.

[38] F. Minami, A. Brückner-Foit, D. Munz and B. Trolldenier, "Estimation procedure for the Weibull parameters used in the local approach," International Journal of Fracture, vol. 54, no. 3, pp. 197-210, 1992.

[39] Harter H. L. and A. H. Moore, "Maximum-likelihood estimation of the parameters of gamma and Weibull populations from complete and from censored samples," Technometrics, vol. 7, no. 4, pp. 639-643, 1965.

[40] Odell P. M., K. M. Anderson and R. B. D'Agostino, "Maximum likelihood estimation for interval-censored data using a Weibull-based accelerated failure time model," Biometrics, pp. 951-959, 1992.

[41] Choi, S.C. and R. Wette, "Maximum likelihood estimation of the parameters of the gamma distribution and their bias," Technometrics, vol. 11, no. 4, pp. 683-690, 1969.

[42] Cacciari, M., G. Mazzanti and G. Montanari, "Comparison of maximum likelihood unbiasing methods for the estimation of the Weibull parameters," IEEE Transactions on Dielectrics and Electrical Insulation, 1996. vol. 3, no. 1, pp. 18-27, DOI: 10.1109/94.485511.

[43] Zanakis S. H. and J. Kyparisis, "A review of maximum likelihood estimation methods for the three-parameter Weibull distribution," Journal of Statistical Computation and Simulation, vol. 25, no. 1-2, pp. 53-73, 1986, DOI: $10.1080 / 00949658608810924$.

[44] Lemon G.H., "Maximum likelihood estimation for the three parameter Weibull distribution based on censored samples," Technometrics, vol. 17, no. 2, pp. 247-254, 1975.

[45] Jiang S., and D. Kececioglu, "Maximum likelihood estimates, from censored data, for mixed-Weibull distributions," IEEE Transactions on Reliability, vol. 41, no. 2, pp. 248-255, 1992, DOI: 10.1109/24.257791.

[46] Mohammadi K., and A. Mostafaeipour, "Using different methods for comprehensive study of wind turbine utilization in Zarrineh, Iran," Energy Conversion and Management, 2013. 65: p. 463-470, 2013, DOI: 10.1016/j.enconman.2012.09.004 
[47] Asir Genc, Murat Erisoglu, Ahmet Pekgor, Galip Oturanc, Arif Hepbasli and Koray Ulgen, "Estimation of wind power potential using Weibull distributio," Energy Sources, vol. 27, no. 9, pp. 809-822, 2015, DOI: $10.1080 / 00908310490450647$.

[48] Kantar Y. M., and B. Şenoğlu, "A comparative study for the location and scale parameters of the Weibull distribution with given shape parameter," Computers and Geosciences, vol. 34, no. 12, pp. 1900-1909, 2008, DOI: 10.1016/j.cageo.2008.04.004

[49] Christos Stathopoulosa Akrivi Kaperonia, George Galanis and George Kallosa, "Wind power prediction based on numerical and statistical models," Journal of Wind Engineering and Industrial Aerodynamics, vol. 112, pp. 25-38, 2013, DOI: 10.1016/j.jweia.2012.09.004.

[50] Junyi Zhou, Ergin Erdem and Gong Li Jing Shi, "Comprehensive evaluation of wind speed distribution models: A case study for North Dakota sites," Energy Conversion and Management, vol. 51, no. 7, pp. 1449-1458, 2010, DOI: 10.1016/j.enconman.2010.01.020.

[51] Dorvlo A. S., "Estimating wind speed distribution," Energy Conversion and Management, vol. 43, no. 17, pp. 2311-2318, 2012, DOI: 10.1016/S0196-8904(01)00182-0

[52] Parajuli A., "A statistical analysis of wind speed and power density based on weibull and rayleigh models of jumla, Nepal," Energy and Power Engineering, vol. 8, no. 7, pp. 271-282, 2016, DOI: 10.4236/epe.2016.87026.

[53] Simiu E., and N. Heckert, "Extreme wind distribution tails: a "peaks over threshold, approach," Journal of Structural Engineering, vol. 122, no. 5, pp. 539-547, 1996.

[54] Pishgar-Komleh S., A. Keyhani and P. Sefeedpari, "Wind speed and power density analysis based on Weibull and Rayleigh distributions (a case study: Firouzkooh county of Iran)," Renewable and Sustainable Energy Reviews, vol. 42, pp. 313-322, 2015, DOI:10.1016/j.rser.2014.10.028.

[55] T. B. M. J. Ouarda, C. Charrona, J.-Y. Shina, P. R. Marpua, A. H. Al-Mandoos, M. H. Al-Tamimi, et. al., "Probability distributions of wind speed in the UAE," Energy Conversion and Management, vol. 93, no. 15, pp. 414-434, 2015, DOI: 10.1016/j.enconman.2015.01.036.

[56] Bhattacharya P., "Weibull distribution for estimating the parameters," in Wind Energy Management, 2011, DOI: $10.5772 / 18151$

[57] Badawi A. S., Hasbullah N. F., Yusoff S. H., Hashim A. H., and Zyoud A., "Novel technique for hill climbing search to reach maximum power point tracking," International Journal Power Electronics and Drive System (IJPEDS),

vol. 11, no. 4, pp. 2019-2029, 2020, DOI: 10.11591/ijpeds.v11.i4.pp2019-2029.

[58] Badawi A. S., "An analytical study for establishment of wind farms in palestine to reach the optimum electrical energy," Thesis, Department of Electrical Engineering, The Islamic University of Gaza, 2013.

[59] Albuhairi M. H., "Assessment and analysis of wind power density in Taiz-republic of Yemen," Ass. Univ. Bull. Environ. Res., vol. 9, no. 2, pp. 13-21, 2006.

[60] Pishgar-Komleh, S.H., A. Keyhani and P. Sefeedpari, "Wind speed and power density analysis based on Weibull and Rayleigh distributions (a case study: Firouzkooh county of Iran)," Renewable and Sustainable Energy Reviews, vol. 42, pp. 313-322, 2015, DOI: 10.1016/j.rser.2014.10.028.

[61] Carlin P.W., "Analytical expressions for maximum wind turbine average power in a Rayleigh wind regime," National Renewable Energy Lab., Golden, CO (United States), 1996.

[62] Badawi A., Kazmi S. A., Boby R. I., Shah M. H., and Matter K, "Resonant circuit response for contactless energy transfer under variable PWM," International Journal of Information and Electronics Engineering, vol. 7, no. 1, pp. 41-47, 2017.

[63] Badawi A. S., Hasbullah N. F., Yusoff S. H., Hashim A., Khan S., and Zyoud A. M,. "Power prediction mode technique for Hill Climbing Search algorithm to reach the maximum power point tracking," In 2020 2nd International Conference on Electrical, Control and Instrumentation Engineering (ICECIE) (pp. 1-7). IEEE.

[64] Badawi A. S., Hasbullaha N. F., Yusoff Y., Khan S., Hashim A., and Zyoud A., et. al., "Evaluation of wind power for electrical energy generation in the Mediterranean coast of Palestine for 14 years," International Journal of Electrical and Computer Engineering (IJECE), vol. 9, no. 4, pp. 2212-1119, 2019, DOI: 10.11591/ijece.v9i4.pp2212-2219.

[65] Badawi A. S., Hasbullah N. F., Yusoff S. H., Hashim A. H., and Zyoud A., "Novel technique for hill climbing search to reach maximum power point tracking," International Journal Power Electronics and Drive System (IJPEDS), vol. 11, no. 4, pp. 2019-2029, 2020, DOI: 10.11591/ijpeds.v11.i4.pp2019-2029.

[66] Badawi A. S., Hasbullah N. F., Yusoff S. H., Hashim A., Khan S., and Zyoud A. M., "Paper review: maximum power point tracking for wind energy conversion system," In 2020 2nd International Conference on Electrical, Control and Instrumentation Engineering (ICECIE), pp. 1-6, IEEE, 2020, DOI:10.1109/ICECIE50279.2020.9309567.

[67] Paulo Alexandre Costa Rocha, Ricardo Coelho de Sousa, Carla Freitas de Andrade, Maria Eugênia and Vieirada Silva "Comparison of seven numerical methods for determining Weibull parameters for wind energy generation in the northeast region of Brazil," Applied Energy, vol. 89, no. 1, pp. 395-400, 2012, DOI: 10.1016/j.apenergy.2011.08.003.

[68] Celik A., A. Makkawi and T. Muneer, "Critical evaluation of wind speed frequency distribution functions," Journal of Renewable and Sustainable Energy, vol. 2, no. 1, 2010, DOI: 10.1063/1.3294127.

[69] Legates D. R., and Gregory J. Mc Cabe Jr., "Evaluating the use of "goodness-of-fit" measures in hydrologic and hydroclimatic model validation," Water Resources Research, vol. 35, no. 1, pp. 2330241, 1999.

[70] J. F. Manwell, Wind energy explained: theory, design and application. 2002. 
[71] Kasra Mohammadi, Omid Alavi, Ali Mostafaeipour, Navid Goudarzi and Mahdi Jalilvand, “Assessing different parameters estimation methods of Weibull distribution to compute wind power density," Energy Conversion and Management, vol. 108: pp. 322-335, 2016, DOI: 10.1016/j.enconman.2015.11.015.

[72] Ohunakin O., M. S. Adaramola and O. M. Oyewola, "Wind energy evaluation for electricity generation using WECS in seven selected locations in Nigeria," Applied Energy, vol. 88, no. 9, pp. 3197-3206, 2011, d oi: 10.1016/j.apenergy.2011.03.022.

[73] MagdielCarrasco-Díaz, David Rivas, Manuel Orozco-Contreras and Orzo Sánchez-Montante, “An assessment of wind power potential along the coast of Tamaulipas, northeastern Mexico," Renewable Energy, vol. 78, pp. 295305, 2015, DOI: 10.1016/j.renene.2015.01.007.

[74] Badawi A. S., Hasbullah N. F., Yusoff S. H., Khan S., Hashim A., Zyoud A., et. al., "Weibull probability distribution of wind speed for Gaza strip for 10 years," Applied Mechanics and Materials, vol. 892, pp. 284-291, 2019 ,

DOI: 10.4028/www.scientific.net/AMM.892.284.

[75] Shu Z., Q. Li and P. Chan, "Statistical analysis of wind characteristics and wind energy potential in Hong Kong," Energy Conversion and Management, vol. 101, pp. 644-657, 2015, DOI: 10.1016/j.enconman.2015.05.070.

[76] A. Tizpar, M. Satkin, M. B. Roshan and Y. Armoudli, "Wind resource assessment and wind power potential of Mil-E Nader region in Sistan and Baluchestan Province, Iran-Part 1: Annual energy estimation," Energy Conversion and Management, vol. 79, pp. 273-280, 2014, DOI: 10.1016/j.enconman.2013.10.004.

[77] Boudia S. M. and O. Guerri, "Investigation of wind power potential at Oran, northwest of Algeria," Energy Conversion and Management, vol. 105, pp. 81-92, 2015, DOI: 10.1016/j.enconman.2015.07.055.

[78] Badawi A., Hasbullaha N., Yusoff S., and Hashim A, "Energy and power estimation for three different locations in Palestine," Indonesian Journal of Electrical Engineering and Computer Science (IJEECS), vol. 5, no. 3, pp. 401-408, 2017, DOI: 10.11591/ijeecs.v14.i3.pp1049-1056.

[79] Akpinar E. K. and S. Akpinar, "An assessment on seasonal analysis of wind energy characteristics and wind turbine characteristics," Energy Conversion and Management, vol. 46, no. 11-12, pp. 1848-1867, 2005, DOI: 10.1016/j.enconman.2004.08.012.

[80] R. O. Fagbenle, J. Katende, O. O. Ajayi and J. O. Okeniyi, "Assessment of wind energy potential of two sites in North-East, Nigeria,” Renewable Energy, vol. 36, no. 4, pp. 1277-1283, 2011, DOI: 10.1016/j.renene.2010.10.003.

[81] Carla Freitas de Andrade, Hely Falcão Maia Neto, Paulo Alexandre Costa Rocha, Maria Eugênia and Vieira da Silva, "An efficiency comparison of numerical methods for determining Weibull parameters for wind energy applications: A new approach applied to the northeast region of Brazil," Energy Conversion and Management, vol. 86, pp. 801-808, 2014, DOI: 10.1016/j.enconman.2014.06.046.

[82] Justus, C. and A. Mikhail, "Height variation of wind speed and wind distributions statistics," Geophysical Research Letters, vol. 3, no. 5, pp. 261-264, 1976, DOI: 10.1029/GL003i005p00261

[83] A. K. Azad, M. G. Rasul, M. M. Alam, S. M. Ameer Uddin, Sukanta Kumar Mondalc, "Analysis of wind energy conversion system using weibull distribution," Procedia Engineering, vol. 90, pp. 725-732, 2014, DOI: 10.1016/j.proeng.2014.11.803.

[84] Arslan, T., Y. M. Bulut, and A. Altın Yavuz, "Comparative study of numerical methods for determining Weibull parameters for wind energy potential," Renewable and Sustainable Energy Reviews, vol. 40, pp. 820-825, 2014, DOI: 10.1016/j.rser.2014.08.009.

[85] Tatiane C. Carneiro, Sofia P. Melo, Paulo C.M. Carvalho, and Arthur Plínio de S. Braga, "Particle swarm optimization method for estimation of Weibull parameters: A case study for the Brazilian northeast region," Renewable Energy, vol. 86, pp. 751-759, 2016, DOI: 10.1016/j.renene.2015.08.060.

[86] Wang, J., J. Hu, and K. Ma, "Wind speed probability distribution estimation and wind energy assessment," Renewable and Sustainable Energy Reviews, vol. 60, pp. 881-899, 2016, DOI: 10.1016/j.rser.2016.01.057.

[87] Yildirim, U., F. Kaya, and A. Gungor, "Comparison of Moment and Energy Trend Factor Methods on Calculating Wind Energy Potential," 16th International Research/Expert Conference "Trends in the Development of Machinery and Associated Technology” TMT 2012, Dubai, UAE, 10-12 September 2012.

[88] Jamil, T. and G.A.A. Shah, "Comparison of wind potential of Ormara and Jiwani (Balochistan), Pakistan," Journal of Basic and Applied Sciences, vol. 12, pp. 411-419, 2015.

[89] Asma zaynah dhunny, Roddy Michel Lollchund, Ravindra Boojhawon and Soonil D.D.V. Rughooputh "Statistical modelling of wind speed data for Mauritius," International Journal of Renewable Energy Research (IJRER), vol. 4, no. 4, pp. 1056-1064, 2014.

[90] Azad, A., M. Rasul, and T. Yusaf, "Statistical diagnosis of the best weibull methods for wind power assessment for agricultural applications,” Energies, vol. 7, no. 5, pp. 3056-3085, 2014, DOI: 10.3390/en7053056.

[91] Rehman, S. and A. Ahmad, "Assessment of wind energy potential for coastal locations of the Kingdom of Saudi Arabia,” Energy, vol. 29, no. 8, pp. 1105-1115, 2004, DOI: 10.1016/j.energy.2004.02.026.

[92] C. G. Justus, W. R. Hargraves, Amir Mikhail and Denise Graber, "Methods for estimating wind speed frequency distributions," Journal of Applied Meteorology, vol. 17, no. 3, pp. 350-353, 1978, DOI: 10.1175/15200450(1978)017<0350:MFEWSF>2.0.CO;2

[93] Adaramola, M.S., M. Agelin-Chaab, and S.S. Paul, "Assessment of wind power generation along the coast of Ghana," Energy Conversion and Management, vol. 77, pp. 61-69, 2014, DOI: 10.1016/j.enconman.2013.09.005.

[94] Fisher, R.A., "Frequency distribution of the values of the correlation coefficient in samples from an indefinitely large population," Biometrika, vol. 10, no. 4, pp. 507-521, 1915 
[95] Stevens MJ, S.P., "The estimation of the parameters of the Weibull wind speed distribution for wind energy utilization purposes," Wind Energy, vol. 3, no. 2, 1979.

[96] Mostafaeipour, A., et. al., "Evaluation of wind energy potential as a power generation source for electricity production in Binalood, Iran. Renewable Energy, 2013. 52: p. 222-229.

[97] Tsang-JungChang, Chun-LungChen, Yi-LongTu, Hung-Te Yeh, Yu-TingWu, "Evaluation of the climate change impact on wind resources in Taiwan Strait," Energy Conversion and Management, vol. 95, pp. 435-445, 2015, DOI: 10.1016/j.enconman.2015.02.033.

[98] Shahnawaz Farhan Khahro, Kavita Tabbassum, Amir Mahmood Soomro, Lei Dong and Xiaozhong Liao, "Evaluation of wind power production prospective and Weibull parameter estimation methods for Babaurband, Sindh Pakistan," Energy Conversion and Management, vol. 78, pp. 956-967, 2014, DOI: 10.1016/j.enconman.2013.06.062

[99] Christofferson, R.D. and D.A. Gillette, "A simple estimator of the shape factor of the two-parameter Weibull distribution," Journal of Climate and Applied Meteorology, vol. 26, no. 2, pp. 323-325, 1987, DOI: 10.1175/15200450(1987)026<0323:ASEOTS>2.0.CO;2.

[100] Shata, A.A. and R. Hanitsch, "The potential of electricity generation on the east coast of Red Sea in Egypt," Renewable Energy, vol. 31, no. 10, pp. 1597-1615, 2006, DOI: 10.1016/j.renene.2005.09.026.

[101] A. K. Azad, M.G. Rasul, Rubayat Islam, and Imrul R. Shishir, "Analysis of wind energy prospect for power generation by three weibull distribution methods," Energy Procedia, vol. 75, pp. 722-727, 2015, DOI: 10.1016/j.egypro.2015.07.499.

[102] Levent Bilir, Mehmet İmir, Y1lser Devrim and AyhanAlbostan, "An investigation on wind energy potential and small scale wind turbine performance at İncek region-Ankara, Turkey," Energy Conversion and Management, vol. 103, pp. 910-923, 2015, DOI: 10.1016/j.enconman.2015.07.017.

[103] Sousa, R.C.d., “Análise e comparação de sete métodos numéricos utilizados na determinação dos parâmetros da curva de Weibull aplicados aos dados de velocidade do vento coletados na cidade de Paracuru-CE e CamocimCE," 2011.

[104] Sarari, B. and J. Gasore, "Monthly Wind Characteristics and Wind Energy in Rwanda," Rwanda Journal, vol. 20, no. 1, pp. 6-23, 2011.

[105] Legates, D.R. and G.J. McCabe, "Evaluating the use of "goodness-of-fit" measures in hydrologic and hydroclimatic model validation," Water Resources Research, vol. 35, no. 1, pp. 233-241, 1999, DOI: 10.1029/1998WR900018.

[106] Mao-Fen Li, Xiao-Ping Tang, Wei Wu, Hong-Bin Liu, "General models for estimating daily global solar radiation for different solar radiation zones in mainland China," Energy Conversion and Management, vol. 70, pp. 139-148, 2013, DOI: 10.1016/j.enconman.2013.03.004.

[107] Jamieson, P., J. Porter, and D. Wilson, "A test of the computer simulation model ARCWHEAT1 on wheat crops grown in New Zealand," Field Crops Research, vol. 27, no. 4, pp. 337-350, 1991, DOI: 10.1016/0378-4290(91) 90040-3.

[108] (PCBS), P.C.B.o.S., Wind Speed Data 2018.

\section{BIOGRAPHIES OF AUTHORS}
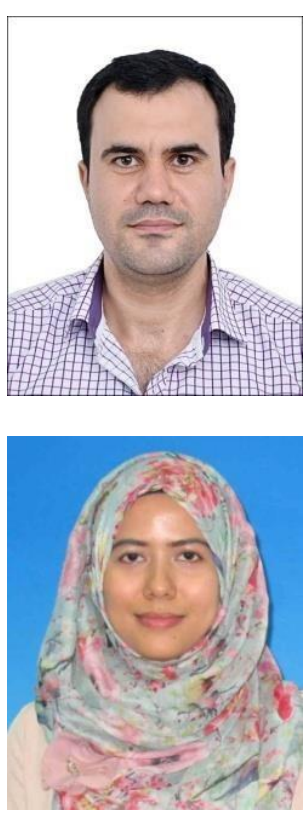

Dr. Ahmed Badawi, have a PhD from International Islamic University Malaysia (IIUM) in 2019. His study is about maximum power point tracking for small scale wind turbine. Dr. Badawi has a Master degree in Wind Energy, Control Dept. (2013) Islamic University of Gaza Palestine. Subject: An Analytical Study for Establishment the Wind Farms in Palestine to Reach the Optimum Electrical Energy. Dr.Badawi is a professional reviewer in IET and Energy Elsevier International Journal.

Dr. Siti Hajar Yusoff received the M.Eng. Degree in electrical engineering (First Class Honors) and the Ph.D. degree in electrical engineering from University of Nottingham, UK, in 2009 and 2014, respectively. In 2015, she became an Assistant Professor in Department of Electrical and Computer Engineering at International Islamic University Malaysia, Gombak. She is now a lecturer in control of power electronics systems and electrical power system. Her research interests include control of power converters and drives, Matrix, multilevel converters, IoT and renewable energy. 

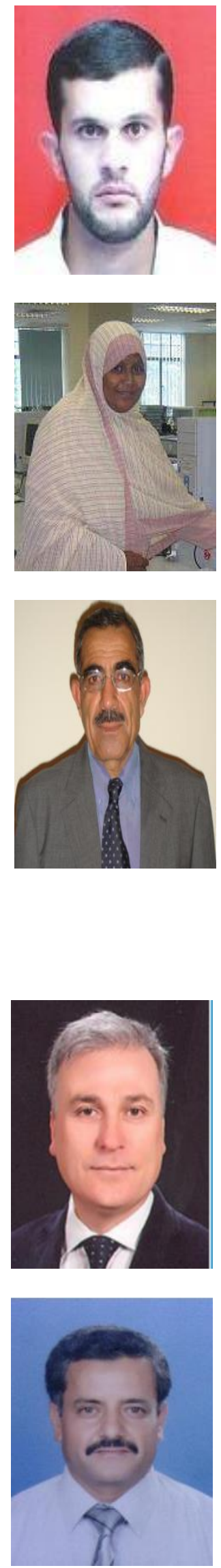

Alhareth Zyoud received his bachelor degree in electrical engineering from Palestine polytechnic university in 2006, and his master degree in communication engineering from international Islamic University Malaysia (IIUM) in 2011. He got a PhD from IIUM at Electrical and Computer Engineering department in 2017. His current research interests are in Interference cancellation, modeling and propagation studies in femtocells $4 \mathrm{G}$ and $5 \mathrm{G}$ networks. He is a member of the IEEE.

Professor Aisha received her PhD in Computer Engineering (2007), M.Sc. in Computer Science (1996), and B.Sc. in Electronics Engineering (1990). She won the best graduating PhD student Award during the IIUM Convocation ceremony in 2007. She joined IIUM in 1997 and currently working as a Professor at the Department of Electrical and Computer Engineering. Professor Aisha has taught several courses related to Communication and Computer Engineering. She is actively participating in curriculum development and program accreditation. She is a member of the Department Board of Studies for several years. She received Best Teacher Award by IIUM during the Quality Day in 2007. She has been appointed as external examiner/visiting professor/adjunct professor at different universities.

Sheroz Khan, being the best graduate of the NWFP University of Engineering and Technology, Sheroz Khan was awarded the university merit scholarship for higher studied in the UK. Completed his MSc in Microelectronics and Computer Engineering from the University of Surrey and $\mathrm{PhD}$ in Electrical Engineering from the University of Strathclyde in 1990 and 1994 respectively. He taught at the NWFP UET (full-time) and at Aeronautical Engineering College Risalpur (NUST, part-time once a week. Since 2000, he has been working within the department of ECE at the IIUM Kuala Lumpur. He has produced $20 \mathrm{M}$ Sc theses and $5 \mathrm{PhD}$ theses under his direct supervision. Currently he is supervising $8 \mathrm{PhD}$ researchers. Sheroz Khan is successfully running a collaboration program under a MoU with the University of LIMOGES (France), and is in kick-start position in the case of IIUM-IIU link Islamabad (Pakistan) program. He is assigned the coordinator position for running the already signed MoU with the Schmalkalden University of Applied Sciences (SUAS), Germany. Sheroz Khan is associated with likeminded colleagues for successful running of International Conferences, and as such he is founder/co-founder/TC/KC chair of IEEE ICCCE, IEEE ICSIMA, and ICISE

Prof. Yılmaz Uyarog ${ }^{\top}$ lu received his B.Sc. in Electrical and Electronics Engineering from the Istanbul Technical University, in 1989, after 5 years period industrial working experience M.Sc. and Ph.D degree in Electrical and Electronics Engineering from the Sakarya University, also postdoc at Hochschule fur Technik Zurich, in 1997, 2002, and 2006, respectively. He is still working at Sakarya University, Electrical and Electronics Engineering department. His research interests are the nonlinear systems and chaos, chaotic synchronization for secure communication and power system quality.

Dr. Mahmoud Salah Ismail received his bachelor degree in Electrical Engineering from University of Jordan, in 1991, and his master degree in Electrical Engineering, Clean Energy and Energy Conservation Engineering from An-Najah National University in 2009. Dr. Mahmoud obtained his PhD in Electrical Engineering, Renewable Energy Engineering from University of Malaya, Malaysia in 2014. He is the head of Electrical Engineering department at Palestine Technical University, Kadoorie, Palestine. His current research interest including Renewable energy, clean energy and Photovoltaic systems. 